\title{
Protein Intake, Prognostic Nutritional Index and Quality of Life in Head and Neck Cancer Patients Undergoing Radiotherapy
}

\author{
Andry Kelvianto ${ }^{1}$, Fiastuti Witjaksono ${ }^{1, *}$, Sri Mutya Sekarutami ${ }^{2}$ \\ ${ }^{1}$ Department of Nutrition, Faculty of Medicine, Universitas Indonesia/Dr. Cipto Mangunkusumo General Hospital, J1. Salemba Raya, Jakarta, Indonesia \\ ${ }^{2}$ Department of Radiotherapy, Faculty of Medicine, Universitas Indonesia/Dr. Cipto Mangunkusumo General Hospital, Jl. Salemba Raya, Jakarta, \\ Indonesia \\ *Corresponding author. E-mail: dr.fiastutiw@gmail.com
}

Received date: Sep 9, 2018; Revised date: Oct 27, 2018; Accepted date: Nov 6, 2018

\section{Abstract}

$\mathrm{B}$ ACKGROUND: It has not been well understood whether the quality and quantity of protein intake could affect the quality of life. Quality of life is associated with nutritional status, but the usage of prognostic nutritional index (PNI) to reflect quality of life of head and neck cancer patients undergoing radiotherapy also still has not been widely studied.

METHODS: A cross sectional study was performed in 61 head and neck cancer patient undergoing radiotherapy. The quantity and quality of protein intake were obtained using semiquantitative food frequency questionnaire (FFQ) which was analized by analyzed using Nutrisurvey 2007, PNI was obtained using a calculation of Onodera's formula based on laboratory data of serum albumin and total lymphocyte count (TLC), and domains of quality of life were obtained from the interview of European Organization for Research and Treatment of Cancer (EORTC) Quality of Life Core Questionnaire (QLQ-C30) and EORTC Quality of Life
Head and Neck module (QLQ-H\&N35) and then calculated to get each domain's score on quality of life.

RESULTS: Patient's median of total protein intake was 1.42 (0.26-4.11) g/kg/day. The median of PNI was 45.9 (29.454.2). Quantity of protein intake was significantly correlated with several symptoms domain of quality of life. PNI was also significantly correlated with one functional domain and two symptom domains of quality of life. This study did not show a significant correlation between quantity and quality of protein intake with PNI.

CONCLUSION: PNI has the potential to reflect quality of life of head and neck cancer patients. Future studies might be beneficial to show the usage of PNI to reflect quality of life, especially involving the progressivity of quality of life.

KEYWORDS: animal protein, chemoradiotherapy, cachexia, quality of life

Indones Biomed J. 2019; 11(1): 70-7

\section{Introduction}

Head and neck cancer remains as the sixth most common cancer worldwide, and is contributed to 350,000 of death per year.(1,2) It likely causes problems in speaking, breathing and eating process for the patients, thus would potentially impair their quality of life.(3-5)

Most cancer patients suffered from a multiple array of inflammation-based syndromes, which also called cancer cachexia, that caused malnutrition by increasing proteolysis, lipolysis and inducing anorexia.(6) The difficulties in eating contributes to the reduction of calorie and protein intake, that will further worsen the problem related to the nutritional status and therapy that cancer patients already had.(5)

Radiotherapy is the most recommended treatment for advanced head and neck cancer, as it provides better locoregional control. The concurrent usage of chemotherapy would increase the effectiveness of radiotherapy by disrupting the cancer cell's repair processes and inducing a 
cell cycle arrest, thus adds better rate of successful treatment. $(7,8)$ Unfortunately, chemotherapy increases a higher risk of complications and worse radiation-related toxicity by twofold and this might cause more disruption in radiotherapy schedule, lower compliance in treatment and also higher rate of admission.(8) These would further impairs the patient's likelihood to achieve the optimal nutritional intake that is recommended by The European Society for Clinical Nutrition and Metabolism (ESPEN) guideline for cancer.(6,9) ESPEN guideline for cancer recommended a minimum daily protein intake of $1.2 \mathrm{~g} / \mathrm{kg} / \mathrm{day}$ to maintain daily function, but as of today, there is no recommendation for protein quality.(9) Studies had shown a changes of certain biologic markers related to protein quality (10-12), thus whether to modify the quality of protein intake for cancer patients to gain benefit remained uncertain.

Prognostic nutritional index (PNI), first coined by Onodera, et al., can be described as a nutritional and inflamation based index derived from serum albumin level and total lymphocyte count (TLC) calculation, of which the two had been used as a marker to determine nutritional status.(13-16) PNI is increasingly used in predicting the prognostic factors, such as survival, metastatic probability, and recurrence rate and chemotherapy adverse events in several cancer studies.(17-21) But no study had investigated the relation of PNI to quality of life. Quality of life, as one of the goal of cancer treatment, is related to nutritional status in cancer studies and can be assessed with various tools (22), but to our knowledge, there is no objective nutritionalrelated markers that has been used to reflect the quality of life in cancer patients. As quality of life is associated with nutritional status, PNI might be able to be used as an objective, nutritional-related marker to reflect the quality of life of head and neck cancer patients. In this study, we attempted to investigate the correlation of PNI with quality of life, and also the correlation of quantity and quality of protein intake with PNI and quality of life.

\section{Methods}

This cross-sectional study took place at the Radiotherapy Department of dr. Cipto Mangunkusumo General Hospital, Jakarta for 4 months during April to July 2018. Estimation of sample size was calculated using the correlation study formula with $\alpha=0,05 ; \beta=0,20 ; r=0,353$, resulting a minimum sample of 61 subjects. Head and neck cancer patients were consecutively recruited after initial screening with inclusion criteria of a head and neck cancer diagnosis on every stadium, age 18-65 years old, currently undergoing radiotherapy treatment with or without concurrent chemotherapy of minimal 30-40 Gy dose and do not have any difficulties standing up. Exclusion criteria were patients having tuberculosis, human immunodeficiency virus (HIV) infection, kidney and liver disorder and also history of stroke and/or bone fracture that disabled them to stand up and do anthropometric measurement. A total of 61 patients were recruited and consented to sign an agreement form after throughout explanation and were able to be analyzed. This study was approved by Ethics Committee of the Faculty of Medicine, Universitas Indonesia with No. 0203/UN2.F1/ ETIK/2018.

Patients were interviewed for obtaining the characteristic data with the help of medical record. Diet pattern for one month were also assessed by interviewing the patients using semi quantitative food frequency questionnaire (FFQ) method with the help of food models instrument. Patients were asked about the amount and frequency of their intake then recorded in structured FFQ form and were subsequently analyzed using Nutrisurvey 2007 program to obtain the total calorie and protein intake per day. The quality of protein intake was also assessed by the ratio of animal protein to plant protein, with $50 \%$ animal protein as the cutoff for a good quality of protein intake. Anthropometric measurements that consisted of body weight and height were obtained using SECA $\AA$ electrodigital scale and ShorrBoard® respectively. Body mass index (BMI) was calculated by the result of weight and height measurements and was categorized into five groups by Asia Pacific criteria. Quality of life evaluation was done by using the standardized questionnaires from the European Organization for Research and Treatment of Cancer (EORTC). The questionnaires used were the EORTC Quality of Life Core Questionnaire (QLQ-C30) and Quality of Life Head and Neck module (QLQ-H\&N35). It was developed for trials involving head and neck cancer patients and was reliable for use in Indonesia by a validation study. Data were calculated and then transformed into scores between 0-100 for each aspects of quality of life.

\section{Laboratory Parameters}

Laboratory data was obtained from one-time blood sample examination. Data consisted of serum albumin level and TLC. Serum albumin level was obtained using Hitachi 917 analyzer with bromocresol green method. TLC was obtained with Sysmex ${ }^{\circledR}$ hematology autoanalyzer. PNI was calculated using serum albumin and TLC, with PNI = $(10 \mathrm{x}$ serum albumin $)+(0.005 \times \mathrm{TLC}) .(13)$ 


\section{Statistical Analysis}

Data were cleaned, processed and analyzed using the Statistical Package for the Social Sciences (SPSS) software version 20.0. Kolmogorov-Smirnov test was used to determine the normality of data distribution with $p>0.05$ for normally distributed data. The correlation of protein intake with PNI, protein intake with quality of life and PNI with quality of life were all analyzed using Spearman Rank test.

\section{Results}

Characteristic of subjects were described in Table 1. Mean age of subjects were $46.3 \pm 12.4$ years old with the highest percentage of over 50 years old (45.9\%). Males were more than females with a ratio of $3: 1$. Nasopharynx $(57.4 \%)$ was the most common source of head and neck cancer in this study. Most subjects present with stage IV cancer $(65.6 \%)$ and $73.8 \%$ of subjects had a combination of radiotherapy with concurrent chemotherapy.

Mean BMI was $20.8 \pm 3.8 \mathrm{~kg} / \mathrm{m}^{2}$ with around third of subjects were in low weight (32.8\%). Assessment of dietary intake revealed that most of the patients $(86.8 \%)$ were using oral route for nutritional intake and ate a median 30.9 (14.9$67.9) \mathrm{kcal} / \mathrm{kg} /$ day of calories and $1.42(0.26-4.11) \mathrm{g} / \mathrm{kg} /$ day of protein. Eighty five point two percent subjects could achieve minimum recommended amount of $25 \mathrm{kcal} / \mathrm{kg}$ per day and $67.2 \%$ could achieve minimum recommended amount of $1.2 \mathrm{~g} / \mathrm{kg}$ per day protein intake. Assessment of protein quality revealed that $70.5 \%$ subjects protein intake consist of more than $50 \%$ animal protein source.

Median of albumin was 4.2 (2.6-5.2) g/dL and mean of TLC was 640.1 \pm 335 . Median of PNI was 45.9 (29.4-54.2). Quality of life were assessed using a scale method from the questionnaire which the patients had to choose from one to four and then calculated to determine the severity of symptoms or improvement in functions. The quality of life in patients were described in Table 2.

This study showed no significant correlation between total protein intake, protein intake per body weight, and quality of protein intake with PNI (Table 3). A significant correlation were found in 7 symptom domains with total protein intake, that are pain (head and neck) $(\mathrm{r}=-0.32$; $p=0.01)$, swallowing ( $\mathrm{r}=-0.37 ; p=0.004)$, social eating $(\mathrm{r}=-0.29 ; p=0.02)$, dry mouth $(\mathrm{r}=-0.41 ; p=0.001)$, sticky saliva $(\mathrm{r}=-0.32 ; p=0.01)$, fatigue $(\mathrm{r}=-0.28 ; p=0.03)$, nausea and vomiting $(\mathrm{r}=-0.26 ; p=0.04)$ and appetite loss $(\mathrm{r}=-0.3$; $p=0.01)$ and in 2 symptom domain with protein intake per body weight that are dry mouth $(\mathrm{r}=-0.3 ; p=0.03)$ and
Table 1. Characteristics of subjects $(n=61)$.

\begin{tabular}{|c|c|}
\hline Variable & n (\%) \\
\hline Age (years) & $46.3 \pm 12.4^{\mathrm{a}}$ \\
\hline $18-29$ & $5(8.2)$ \\
\hline $30-39$ & 15 (24.6) \\
\hline $40-49$ & $13(21.3)$ \\
\hline$\geq 50$ & $28(45.9)$ \\
\hline \multicolumn{2}{|l|}{ Gender } \\
\hline Male & $47(77.0)$ \\
\hline Female & $14(23.0)$ \\
\hline
\end{tabular}

Cancer location

Nasopharynx

$35(57.4)$

Larynx

$13(21.3)$

Oral cavity

$10(16.4)$

Nasal cavity

$3(4.9)$

Stage

I $\quad 0(0)$

II $2(3.3)$

III $17(27.9)$

IV $\quad 40(65.6)$

Unknown $2(3.3)$

Treatment modality

Radiotherapy only

$16(26.2)$

\begin{tabular}{ll} 
Chemoradiotherapy & $45(73.8)$ \\
\hline BMI $\left(\mathrm{kg} / \mathrm{m}^{2}\right)$ & $20.8 \pm 3.8^{\mathrm{a}}$
\end{tabular}

Nutritional status by BMI

Underweight

$20(32.8)$

Normoweight

$26(42.6)$

Overweight

$15(24.6)$

\begin{tabular}{lc}
\hline Daily calorie intake $(\mathrm{kka} / \mathrm{kgBB} /$ day $)$ & $30.9(14.9-67.8)^{\mathrm{b}}$ \\
\hline Categories of calorie intake & \\
$\geq 25 \mathrm{kcal} / \mathrm{kg} /$ day & $52(85.2)$ \\
$<25 \mathrm{kcal} / \mathrm{kg} /$ day & $9(14.8)$
\end{tabular}

\begin{tabular}{lc}
\hline Daily total protein intake (g/day) & $78.8(11.6-242.9)^{\mathrm{b}}$ \\
\hline Protein intake per body weight $(\mathrm{g} / \mathrm{kgBB} /$ day $)$ & $1.42(0.26-4.11)^{\mathrm{b}}$ \\
\hline Categories of protein intake & \\
$\quad \geq 1.2 \mathrm{~g} / \mathrm{kg} /$ day & $41(67.2)$ \\
$\quad<1.2 \mathrm{~g} / \mathrm{kg} /$ day & $20(32.8)$
\end{tabular}

Ratio of animal protein source

$<50 \% \quad 18(29.5)$

$\geq 50 \% \quad 43(70.5)$

NGT usage

Yes $\quad 8(13.1)$

No $\quad 53(86.8)$

Parenteral usage

Yes $0(0)$

No $61(100)$

\begin{tabular}{lc}
\hline Serum albumin $(\mathrm{g} / \mathrm{dL})$ & $4.2(2.6-5.2)^{\mathrm{b}}$ \\
\hline TLC & $640.1 \pm 335^{\mathrm{a}}$ \\
\hline PNI & $45.9(29.4-54.2)^{\mathrm{b}}$ \\
\hline
\end{tabular}

${ }^{\mathrm{a}}$ Mean \pm standard deviation; ${ }^{\mathrm{b}}$ Median (minimum- maximum). 
Table 2. Quality of life score by EORTC QLQ-C30 and EORTC QLQ-H\&N35.

\begin{tabular}{lc}
\hline \multicolumn{1}{c}{ Criteria } & $\begin{array}{c}\text { Score } \\
\text { Median (Min-Max) }\end{array}$ \\
\hline Quality of life by EORTC QLQ C-30 & \\
Global health status & $58.3(0-100)$ \\
Physical function & $66.7(20-100)$ \\
Role function & $66.7(0-100)$ \\
Emotional function & $75(8.3-100)$ \\
Cognitive function & $100(16.7-100)$ \\
Social function & $66.7(0-100)$ \\
Fatigue & $16.7(0-66.7)$ \\
Nausea and vomiting & $16.7(0-66.7)$ \\
Pain & $16.7(0-66.7)$ \\
Dyspnea & $0(0-50)$ \\
Insomnia & $0(0-100)$ \\
Appetite loss & $33.3(0-100)$ \\
Constipation & $0(0-100)$ \\
Diarrhea & $0(0-33.3)$ \\
\hline Quality of life by EORTC QLQ H\&N35 & \\
Pain (head and neck) & $25(0-83.3)$ \\
Swallowing & $41.6(0-100)$ \\
Senses problem & $50(0-100)$ \\
Speech problem & $44.4(0-100)$ \\
Trouble with social eating & $50(0-100)$ \\
Teeth & $0(0-100)$ \\
Opening mouth & $33.3(0-100)$ \\
Dry mouth & $66.7(0-100)$ \\
Sticky saliva & $66.7(0-100)$ \\
Coughing & $33.3(0-100)$ \\
Felt ill & $33.3(0-100)$ \\
\hline
\end{tabular}

appetite loss $(\mathrm{r}=-0.3 ; p=0.03)$ but none was found in quality of protein intake (Table 4). This study also investigated the correlation between PNI and aspects of quality of life based on EORTC QLQ-C30 and EORTC QLQ-H\&N35. There were significant correlation found between physical function $(\mathrm{r}=0.378 ; p=0.003)$, opening mouth $(\mathrm{r}=-0.325 ; p=0.011)$ and dyspnea $(\mathrm{r}=-0.257 ; p=0.045)$ with PNI. Several other symptom domains were also negatively correlated with PNI, althought not statistically significant (Table 5).

\section{Discussion}

The highest incidences of head and neck cancer in this study were found in subjects of more than 50 years old. This result was also shown in other studies, which most of the subjects were male. $(7,23)$ Gupta, et al., who investigated the agestandardized incidence rate (ASIR) in head and neck cancer patients in several regions showed a consistently higher rate of ASIR in males compared to females in most regions.(24) The most common risk factors for head and neck cancer were tobacco use and alcohol consumption, which were higher in male than female and these might be the reason of the higher incidence in males over the world.(25) Most of other studies in America and Europe did not show that nasopharynx was the most common primary location, contrary to the result of this study.(25-27) But Rahmaeni, et al., who conducted a study in the other region of Indonesia, also had a similar findings.(23) Other study by Shield, et al., who investigated the proportional cases of lip, oral cavity, and pharyngeal cancer (LOCP) in various regions over the world showed a highest number of nasopharyngeal cancer in most Asian regions.(28)

Data for one month of calorie and protein intake were obtained from interview using semiquantitative FFQ structured form with trained investigator. The data showed that most subjects could achieve adequate minimum amount of calorie and protein intake, which are $25 \mathrm{kcal} / \mathrm{kg} /$ day and $1.2 \mathrm{~g} / \mathrm{kg} /$ day respectively according to ESPEN guideline. (7) This result might be in association with subject's BMI status, as in only third of the subjects were underweight. All of the subjects in present study were given pre-therapy nutritional education with a weekly routine follow-up by the general practitioners that were trained in clinical nutrition background. Nutritional education is recommended by ESPEN guideline as the first line of intervention in cancer treatment and has been linked with several favourable outcomes.(9) Usage of enteral route was lacking in this study, as only $13.1 \%$ subjects were using nasogastric tube during course of treatment. Currently, the use of enteral route is not the standard protocol in clinical pathway at the current institution althought there is proof that patients using nasogastric tube suffered less reduction in body weight compared to oral route.(29) We, therefore, suggest that the usage of enteral route to be a consideration in the future protocol to maximize outcomes.

Table 3. Correlation between protein intake and PNI.

\begin{tabular}{lcc}
\hline \multirow{2}{*}{ Variable } & \multicolumn{2}{c}{ Prognostic Nutritional Index } \\
\cline { 2 - 3 } & $\mathbf{r}$ & $\boldsymbol{p}$ \\
\hline Total protein intake & 0.036 & 0.785 \\
Protein intake per body weight & -0.11 & 0.39 \\
Quality of protein intake & -0.088 & 0.5 \\
\hline
\end{tabular}







Protein quality was one of the variables of interest in this study. Animal protein source contain varied amino acid that is relatively more fitting to human tissues utilization, specifically to several amino acids like cysteine, methionine, tryptophan, glycine and threonine.(30) Study showed a benefit for consumption of animal protein sources to muscle mass as it provided better retention and optimal muscle protein synthesis which also might be a benefit for cancer patients. The study also showed an inadequate intake of certain amino acids in elderly if the ratio of animal to plant protein was under $65 \%$.(30) Other study by Gavelle, et al., that investigated the ratio of animal to plant protein by its relation to protein adequacy in French population showed that an inadequate protein intake along with amino acid lysine were present after the $50 \%$ ratio to higher plant protein onward.(31) The recommendation from Food and Agriculture Organization (FAO) is to use Digestible Indispensable Amino Acid Scores (DIAAS) to determine protein quality in each food source based on the limiting amino acid that can be digested and absorbed at ileum.(32) However, we cannot find the database to be used in our study so the DIAAS method remains unviable in present study.

To our knowledge, there are no current guidelines that include protein quality recommendation specifically in cancer patients, so we used the $50 \%$ ratio as our cut-off point for a good quality of protein intake based on the above mentioned study. But then, the difference in food tables used in Gavelle, et al., study, which primarily was for French food sources, and the food tables used in Indonesia might warrant a different result to be a matter of concern.(31)

The result of PNI was derived from calculation of serum albumin level and TLC. Albumin had been used to determine the protein level in several studies and has been linked to prognosis of cancer patients, mainly survival rate. $(33,34)$ The variation in serum albumin level on various subjects might be the majority result of the inflammation process which would increase the level of proinflammatory markers, as it is consistently present in cancer patients. As a result, the proinflammatory markers would modulate the increment in acute phase proteins with a subsequent decrease in hepatic albumin synthesis.(35)

Thus, it was suggested that the adequate supply of amino acids that enhance serum albumin availability would be the matter of consideration. TLC was also decreased in almost all cancer patients receiving radiotherapy as it is one of the most sensitive to radiation especially to the area that is abundant in lymphoid tissues like the head and neck area. $(36,37)$ The radiation dose up to 50 Gy would significantly decrease the circulating lymphocyte.(36) Kuss, et al., found that the decreasing lymphocytes were of immunological importance.(37) In present study, PNI was meant to be a surrogate of both nutritional and immunological status so the changes in these two components resulted in variability in subjects and might have a better value if adequate calories and protein intake were warranted as in other nutritional status markers. This might also explain the result of this present study that most subjects could achieve adequate daily calorie and protein intake, so the variability of PNI might be minimal and not adequate to show a difference among subjects. Further studies should address this issue by doing several adjustments to have even more optimal results.

Several aspects in quality of life were significantly correlated in this study to PNI and protein intake and mostly were from symptomatic aspects. This mentioned symptomps were thought to have an impact to patient's eating process as they are in term to the oral mucositis that might possibly caused dysphagia and it might impact some of the calorie and protein intake that the subjects had.(38) Zahn, et al., showed less degree of oral mucositis with better calorie and protein intake and most probably resulted in better quality of life. That previous study also state that wound healing, which was one of the main problems in oral mucositis, would have better rate of healing if adequate intake was achieved by minimal of one week despite the patient's current nutritional status.(26) The current recommendation for treatment of radiotherapy-induced oral mucositis were maintaining the oral hygiene and usage of pain medication. (29) Thus, suggestion to also ensure optimal nutritional intake might confer a better outcome with a simple strategy like the nutritional education and a routine follow-up period. However, in this present study, we cannot fully affirm whether it was the oral mucositis first that caused the reduction of nutritional intake, PNI and quality of life or the low nutritional intake first that might be the cause of the worse oral mucositis, lower PNI and quality of life.

Domains of quality of life that is significantly correlated with PNI were physical function, open mouth and dyspnea. Study by Sayer, et al., that assessed hang-grip as a marker of physical function that is related to nutritional status to quality of life found that lower hand grip score is associated with lower quality of life especially in elderly. (39) In head and neck cancer patients that is suffering from dysphagia, silent aspiration is quite common and this is strongly related to pneumonia and death.(7) This might be the result of low immunity status that can be shown by low TLC and it happened to all of the subjects in this study as 
a cause of decreased nutritional intake and the radiation. This might imply that PNI can predict the risk of having complication of aspiration and by increasing PNI would decrease the risk.

Although not significant, further analysis of the study also showed a consistent direction of correlation with either PNI and protein intake to the aspects of quality of life. This strongly suggest that the higher PNI would resulted in better functional status and less symptoms severity and might be enhanced by optimal protein intake even more. By this study, we could suggest that the usage of PNI to predict head and neck cancer patient's quality of life is promising, however it needs more studies and evidence to be affirmed. Another suggestion would be using several follow-up periods of quality of life assessment as a serial investigations to look at the rate of reduction in quality of life as showed in previous study that most head and neck cancer patients would suffer for progressive reduction in quality of life along with radiation period.(40)

\section{Conclusion}

This present study showed a significant correlation between PNI and protein intake to several domains of quality of life which mostly were a symptomatic aspects. Optimizing daily protein intake might have a benefit in reducing toxicity-related symptoms in radiotherapy. PNI remains the promising nutritional-based marker to be used to reflect quality of life although more evidence might be needed to ascertain this. We suggest that further studies should consider of prospective study design to investigate the severity of symptoms and functional status in a time-related manner, preferably with several follow-up periods.

\section{References}

1. Vigneswaran N, Williams MD. Epidemiologic trends in head and neck cancer and aids in diagnosis. Oral Maxillofac Surg Clin North Am. 2014; 26: 123-41.

2. Wissinger E, Griebsch I, Lungershausen J, Foster T, Pashos CL. The economic burden of head and neck cancer: a systematic literature review. Pharmacoeconomics. 2014; 32: 865-82.

3. Wallengren O, Lundholm K, Bosaeus I. Diagnostic criteria of cancer cachexia: relation to quality of life, exercise capacity and survival in unselected palliative care patients. Support Care Cancer. 2013; 21: $1569-77$

4. Gorenc M, Kozjek NR, Strojan P. Malnutrition and cachexia in patients with head and neck cancer treated with (chemo) radiotherapy. Reports Pract Oncol Radiother. 2015; 20: 249-58.
5. Barajas Galindo DE, Vidal-Casariego A, Calleja-Fernandez A, Hernandez-Moreno A, Pintor de la Maza B, Pedraza-Lorenzo M, et al. Appetite disorders in cancer patients: Impact on nutritional status and quality of life. Appetite. 2017; 114: 23-7.

6. Wallengren O, Lundholm K, Bosaeus I. Diagnostic criteria of cancer cachexia: Relation to quality of life, exercise capacity and survival in unselected palliative care patients. Support Care Cancer. 2013; 21: $1569-77$.

7. Nguyen NP, Moltz CC, Frank C, Vos P, Smith HJ, Karlsson U, et al. Dysphagia following chemoradiation for locally advanced head and neck cancer. Ann Oncol. 2004; 15: 383-8.

8. Iqbal MS, Chaw C, Kovarik J, Aslam S, Jackson A, Kelly J, et al. Primary concurrent chemoradiation in head and neck cancers with weekly cisplatin chemotherapy: Analysis of compliance, toxicity and survival. Int Arch Otorhinolaryngol. 2017; 21: 171-7.

9. Arends J, Bachmann P, Baracos V, Barthelemy N, Bertz H, Bozzetti $\mathrm{F}$, et al. ESPEN guidelines on nutrition in cancer patients. Clin Nutr. 2017; 36: 11-48.

10. Loenneke JP, Wilson JM, Manninen AH, Wray ME, Barnes JT, Pujol TJ. Quality protein intake is inversely related with abdominal fat. Nutr Metab. 2012; 9: 5. doi: 10.1186/1743-7075-9-5.

11. Watanabe M, Higashiyama A, Kokubo Y, Ono Y, Okayama A, Okamura T. Protein intakes and serum albumin levels in a Japanese general population: NIPPON DATA90. J Epidemiol. 2010; 20(Suppl 3): S531-6.

12. Gupta KL, Sahni N, Rana SV, Prasad R, Bhalla AK. Impact of balancing grams of quality protein intake on nutritional status and quality of life in CKD patients. Kidney Res Clin Pract. 2012; 31: A33. doi: 10.1016/j.krcp.2012.04.390.

13. Onodera T, Goseki N, Kosaki G. Prognostic nutritional index in gastrointestinal surgery of malnourished cancer patients. Nihon Geka Gakkai zasshi. 1984; 85: 1001-5.

14. Bharadwaj S, Ginoya S, Tandon P, Gohel TD, Guirguis J, Vallabh H, et al. Malnutrition: laboratory markers vs nutritional assessment. Gastroenterol Rep. 2016; 4: gow013. doi: 10.1093/gastro/gow013.

15. Robinson R. Low serum albumin and total lymphocyte count as predictors of 30 day hospital readmission in patients 65 years of age or older. PeerJ. 2015; 3: e1181. doi: 10.7717/peerj.1181.

16. González Madroño A, Mancha A, Rodríguez FJ, Ulibarri JI De, Culebras J. The use of biochemical and immunological parameters in nutritional screening and assessment. Nutr Hosp. 2011; 26: 594 601.

17. Du XJ, Tang LL, Mao YP, Guo R, Sun Y, Lin AH, et al. Value of the prognostic nutritional index and weight loss in predicting metastasis and long-term mortality in nasopharyngeal carcinoma. J Transl Med. 2015; 13: 364. doi: 10.1186/s12967-015-0729-0.

18. Nozoe T, Ninomiya M, Maeda T, Matsukuma A, Nakashima H, Ezaki T. Prognostic nutritional index: A tool to predict the biological aggressiveness of gastric carcinoma. Surg Today. 2010; 40: 440-3

19. Broggi MS, Patil D, Baum Y, Nieh PT, Alemozaffar M, Pattaras JG, et al. Onodera's prognostic nutritional index as an independent prognostic factor in clear cell renal cell carcinoma. Urology. 2016; 96: 99-105.

20. Peng W, Li C, Wen TF, Yan LN, Li B, Wang WT, et al. Postoperative prognostic nutritional index change is an independent predictor of survival in patients with small hepatocellular carcinoma. J Surg. 2016; 212: 122-7.

21. Sun J, Wang D, Mei Y, Jin H, Zhu K, Liu X, et al. Value of the prognostic nutritional index in advanced gastric cancer treated with preoperative chemotherapy. J Surg Res. 2017; 209: 37-44. 
22. Lis CG, Gupta D, Lammersfeld CA, Markman M, Vashi PG. Role of nutritional status in predicting quality of life outcomes in cancer - a systematic review of the epidemiological literature. Nutr J. 2012; 11: 27. doi: 10.1186/1475-2891-11-27.

23. Rahmaeni, Kuhuwael F, Rahardjo SP. Validitas dan reliabilitas EORTC QLQ-H \& N35 sebagai alat ukur kualitas hidup penderita kanker kepala leher. Oto Rhino Laryngol Indones. 2015; 45: 14250 .

24. Gupta B, Johnson NW, Kumar N. Global epidemiology of head and neck cancers: a continuing challenge. Oncology. 2016; 91: 13-23.

25. Rettig EM, D'Souza G. Epidemiology of head and neck cancer. Surg Oncol Clin N Am. 2015; 24: 379-96.

26. Zahn KL, Wong G, Bedrick EJ, Poston DG, Schroeder TM, Bauman JE. Relationship of protein and calorie intake to the severity of oral mucositis in patients with head and neck cancer receiving radiation therapy. Head Neck. 2012; 34: 655-62.

27. Larsson M, Hedelin B, Johansson I, Athlin E. Eating problems and weight loss for patients with head and neck cancer: a chart review from diagnosis until one year after treatment. Cancer Nursing. 2005; 28: 425-35.

28. Shield KD, Ferlay J, Jemal A, Sankaranarayanan R. The global incidence of lip, oral cavity, and pharyngeal cancers by subsite in 2012. CA Cancer J Clin. 2017; 67: 51-64.

29. Garg S, Yoo J, Winquist E. Nutritional support for head and neck cancer patients receiving radiotherapy: a systematic review. Support Care Cancer. 2010; 18: 667-77.

30. Wu G. Dietary protein intake and human health. Food Funct. 2016; 7: 1251-65.

31. de Gavelle E, Huneau JF, Bianchi CM, Verger EO, Mariotti F. Protein adequacy is primarily a matter of protein quantity, not quality: Modeling an increase in plant: Animal protein ratio in French adults. Nutrients. 2017; 9: pii: E1333. doi: 10.3390/ nu9121333.

32. Food and Agriculture Organization. Dietary protein quality evaluation in human nutrition: Report of an FAO Expert Consultation. Auckland: Food and Agriculrure Organization; 2011.

33. Bobdey S, Jain A, Sathwara J. Pretreatment serum albumin: a prognostic indicator of survival in oral cancer. Int J Res Med Sci. 2016; 44: 2135-41.

34. Gupta D, Lis CG. Pretreatment serum albumin as a predictor of cancer survival: A systematic review of the epidemiological literature. Nutr J. 2010; 9: 69. doi: 10.1186/1475-2891-9-69.

35. Aoyagi T, Terracina KP, Raza A, Matsubara H, Takabe K. Cancer cachexia, mechanism and treatment. World J Gastrointest Oncol. 2015; 7: 17-29.

36. Verastegui EL, Morales RB, Barrera-Franco JL, Poitevin AC, Hadden J. Long-term immune dysfunction after radiotherapy to the head and neck area. Int Immunopharmacol. 2003; 3: 1093-104.

37. Kuss, I, Hathaway, B, Ferris, RL, Gooding, W, Whiteside TL. Imbalance in absolute counts of T lymphocyte subsets in patients with head and neck cancer and its relation to disease1. Curr Res Head Neck Cancer. 2004; 62: 161-72.

38. Ganzer H, Touger-Decker R, Byham-Gray L, Murphy BA, Epstein JB. The eating experience after treatment for head and neck cancer: A review of the literature. Oral Oncol. 2015; 51: 634-42.

39. Sayer AA, Syddall HE, Martin HJ, Dennison EM, Roberts HC, Cooper C. Is grip strength associated with health-related quality of life? Findings from the Hertfordshire Cohort Study. Age Ageing. 2006; 35: 409-15.

40. Kelly C, Paleri V, Downs C, Shah R. Deterioration in quality of life and depressive symptoms during radiation therapy for head and neck cancer. Otolaryngol Head Neck Surg. 2007; 136: 108-11. 